\title{
As estratégias de comunicação da Netflix brasil e o engajamento do público nas redes sociais da Internet
}

\author{
Mariana Vernizi Gonçalves ${ }^{1}$ \\ Fabiana Pelinson ${ }^{2}$
}

\begin{abstract}
Resumo
Este artigo objetiva apresentar as estratégias de comunicação digital da Netflix Brasil em três redes sociais da Internet - Facebook, Instagram e Twitter - e caracterizar o engajamento dos usuários com tais estratégias. Para isso, realiza-se uma pesquisa quantitativa-qualitativa, de cunho descritivo e explicativo, ao analisar 169 postagens da Netflix Brasil. A discussão dos dados é orientada pela Análise de Conteúdo e pelo Fluxograma de Engajamento. Os resultados evidenciam o uso de seis estratégias comunicacionais, por ordem de frequência: informações sobre lançamentos, informações sobre a empresa, abordagem de humor, utilização de memes, busca por interação e ativismo social. Além disso, o engajamento dos seguidores se caracteriza entre os níveis de envolvimento e interação, com nuances de intimidade.
\end{abstract}

Palavras-chave: Netflix Brasil; Comunicação digital; Engajamento.

\begin{abstract}
This article aims to present the digital communication strategies of Netflix Brazil on three Internet social networks - Facebook, Instagram and Twitter - and to characterize the engagement of users with such communication strategies. For this, a quantitative-qualitative research, of a descriptive and explanatory nature, is carried out, analyzing 169 posts from Netflix Brazil. The discussion of the data is guided by the Content Analysis and the Engagement Flowchart. The results show six communication strategies, in order of frequency: information about launches, information about the company, approach to humor, use of memes, search for interaction and social activism. In addition, the engagement of followers is characterized by levels of involvement and interaction, with nuances of intimacy.
\end{abstract}

Keywords: Netflix Brazil; Digital communication; Engagement.

\footnotetext{
${ }^{1}$ Graduada em Comunicação Social - Publicidade e Propaganda pelo Instituto Superior Litoral do Paraná. maarivg@ @otmail.com

${ }^{2}$ Doutora em Ciências Sociais Aplicadas pela Universidade Estadual de Ponta Grossa (UEPG) e mestra em Comunicação pela Universidade Federal do Paraná (UFPR).

fabianapelinson@gmail.com
} 


\section{VOZES $_{\text {\&IÁLORO }}^{\mid}$}

Itajaí, V. 20, n.01, jan-jun 2021

\section{Introdução}

Os avanços das tecnologias digitais, das mídias virtuais e das redes sociais presentes no ciberespaço adquiriram centralidade no cotidiano e nas relações estabelecidas pelos indivíduos. Isso têm modificado o modo como as pessoas têm construído a realidade, organizado seus grupos, estabelecido relacionamentos e comunicações, assim como suas práticas de consumo e suas experiências com as marcas.

É este ciberespaço que notabilizou a era da cibercultura como a nova forma da cultura contemporânea. Lemos (2002, p. 54) assegura que o fenômeno técnico eclode de modo extensivo a partir da última fase da modernidade, instaurando "a fase da ubiquidade, a fase da simulação, a fase da cibercultura”. Nessa nova forma de interconexões, distintas formas de comunicação, a cultura, os modos de organização, a vivência das práticas sociais e os comportamentos passam a ser reorientados.

Em virtude desse novo comportamento dos consumidores - que estão recorrentemente emitindo comentários, opiniões e avaliações sobre os produtos e as informações na Internet -, as empresas vêm moldando-se às demandas do público e readequando suas estratégias de comunicação. Essas estratégias, por sua vez, têm um objetivo que vai além de oferecer um produto ou serviço de qualidade, mas oferecer experiências aos consumidores.

Com um serviço inteiramente disponível em meio digital, a Netflix é uma plataforma que atua em escala mundial no serviço de entretenimento mediado por streaming, onde oferece conteúdos audiovisuais para uma comunidade que desenvolve o hábito de consumi-los e até compartilhá-los em outras plataformas. Diversas pesquisas e levantamentos (AMARAL, 2016; RICCIULLI, 2017; NORTON, 2018) apontam a efetividade da Netflix, seja na produção de conteúdo ou nas estratégias de engajamento.

A partir destas reflexões, apresentamos como problema de pesquisa dois aspectos específicos: 1) as estratégias de comunicação utilizadas pela empresa e 2) como essas estratégias resultam em níveis diferentes de engajamento nas plataformas de rede social Facebook, Instagram e Twitter. Decorrente disso, o objetivo geral consiste em apresentar as estratégias de comunicação digital da Netflix Brasil nas três redes sociais mais utilizadas na Internet e, a partir disso, caracterizar o engajamento dos usuários com as estratégias de comunicação em cada uma das três redes.

Para isso, conduzimos uma pesquisa quantitativa-qualitativa, de cunho descritivo e explicativo, analisando as postagens da Netflix Brasil em suas páginas no Facebook, no Instagram e no Twitter na delimitação temporal de junho a julho de 2019. A discussão dos dados é orientada pela Análise de Conteúdo (BARDIN, 2011), a partir das estratégias de engajamento no cruzamento das considerações de Haven (2007) e Li (2011). 


\section{VOZES $_{\text {\&IÁLORO }}^{\mid}$}

Itajaí, V. 20, n.01, jan-jun 2021

\section{Procedimentos metodológicos}

Considerando o objetivo de apresentar as estratégias de comunicação digital utilizadas pela Netflix Brasil e compreender como resultam em engajamento, conduzimos uma pesquisa quantitativa-qualitativa, de cunho descritivo e explicativo. No que concerne aos procedimentos técnicos, a pesquisa se caracteriza como um estudo de caso.

O objeto de estudo são as redes sociais da Netflix Brasil - Facebook, Instagram e Twitter. A coleta de dados das postagens da Netflix Brasil em cada uma das redes sociais no período de um mês deu-se pelo método da observação simples do conteúdo das postagens e do volume de comentários e de reações, junto à análise qualitativa do levantamento manual destes materiais a partir da delimitação temática e temporal.

O critério estabelecido é o de observação dos mapas sociais - ou seja, postagens, curtidas, comentários e compartilhamentos - sem qualquer participação com os conteúdos analisados durante o período de um mês (01 de junho a 01 de julho de 2019) ${ }^{3}$, representando um total de 169 postagens, compostas por vídeos, imagens, textos e GIFs. Deste total, 61 postagens foram coletadas do Facebook, 44 do Instagram e 64 do Twitter.

Por entender que estas publicações, juntamente aos comentários, respostas e reações, são, sobretudo, conteúdo comunicacional, nos apropriamos da Análise de Conteúdo de Bardin (2011). Para analisar o conteúdo de um texto, Bardin (2011, p. 95) propõe um método de análise que se desdobra em três fases: 1) a pré-análise; 2) a exploração do material; 3) o tratamento dos resultados, a inferência e a interpretação. Após a pré-análise dos dados, delimitamos as unidades de análise para depois categorizá-las de maneira que representem as esferas das estratégias de engajamento.

Nesta pesquisa, as Unidades de Registro (UR) são as unidades de significação ou então os indicadores das estratégias de comunicação da Netflix Brasil, de modo que as UR estabelecidas correspondem aos elementos-chave utilizados para gerar engajamento em cada uma das publicações e nas respostas aos principais comentários registrados nas redes sociais da Netflix Brasil. Já as Unidades de Contexto (UC) são as publicações e comentários de onde extraímos as UR submetidas às categorias de análise. Deste modo, definimos como UC toda publicação - em texto, vídeo ou imagem.

Estabelecidas as UR e as UC, partimos para a etapa de classificar as UR proeminentes, que servem como viés para as categorias inferidas a posteriori, a partir da

\footnotetext{
${ }^{3}$ A delimitação temporal se deu pela conquista da plataforma, neste curto período, de dois recordes de audiência com duas de suas produções originais. A primeira delas foi com o filme "Mistério no Mediterrâneo" (2019), disponibilizado na plataforma no dia 14 de junho de 2019 e que, em apenas três dias, foi assistido por mais de 30 milhões de usuários da Netflix, a maior estreia de filmes produzidos pela plataforma até então. A segunda delas foi com a série "Olhos Que Condenam" (2019), que foi a mais assistida durante duas semanas ininterruptas desde sua estreia. Estes recordes, junto aos anúncios de séries queridas pelo público nas redes sociais, justificam a opção por este recorte temporal.
} 


\section{VOZES \\ ¿DIÁl DCo}

Itajaí, V. 20, n.01, jan-jun 2021

coleta destes materiais empíricos. Para esta classificação, a associação das UR é feita pelo princípio da presença ou ausência das estratégias nas UC. Isto é relevante pois a frequência de cada UR nas UC tem relação com as particularidades deste contexto, sendo uma observação significativa para a análise, principalmente levando em consideração que as UR mais frequentes e presentes são reunidas em categorias intituladas genericamente, sendo constituídas pelos aspectos mais corriqueiros dentre estes elementos.

\section{Análise e discussão dos resultados}

A partir da coleta dos dados, primeiramente identificamos as estratégias de comunicação da Netflix Brasil em busca de engajamento. Ao verificar as publicações no Facebook, no Instagram e no Twitter, chegamos ao resultado de que as principais estratégias de engajamento utilizadas durante o período de coleta foram: 1) informações sobre lançamentos; 2) informações sobre a empresa; 3) abordagem de humor; 4) utilização de memes; 5) busca por interação e 6) ativismo social.

As informações sobre lançamentos se caracterizam como publicações que anunciam os lançamentos ou renovações de séries, filmes, documentários, etc. Essa estratégia é a mais utilizada, pois aborda novidades geralmente muito esperadas pelo público. Já a segunda estratégia, de informações sobre a empresa, se refere à divulgação de dados gerais, como recordes de audiência, conteúdos que já estão em seu catálogo ou até indicações ao público, que não são novidades tão esperadas pelos espectadores.

A abordagem de humor é a terceira categoria identificada e é evidenciada, majoritariamente, em contextos contendo algum trocadilho ou ironia que o público seja capaz de identificar. Diversas vezes, essa abordagem humorística está diretamente ligada à utilização de memes, quarta categoria identificada. Os memes são caracterizados por terem o caráter de entreter, satirizar, referenciar ou apenas expressar uma opinião e são demasiadamente replicados pelos atores nas redes sociais da Internet. No caso da Netflix Brasil, utiliza-se um elemento engraçado (como uma piada, um termo em alta, uma ideia, uma mensagem ou até mesmo uma informação em tom de humor) com o objetivo de atingir seu público com um conteúdo positivo, humorístico e de senso e opinião em comum.

Apesar de todas as estratégias buscarem uma certa interação, a quinta estratégia se categoriza pelo ato de a Netflix Brasil explicitamente convidar o seguidor a conversar ou expressar opinião. Isso ocorre, por exemplo, quando a empresa dá espaço para seus seguidores compartilharem teorias e ideais sobre as produções futuras que entrarão na plataforma. Por fim, a estratégia de engajar os seguidores por meio do ativismo social encontra-se em postagens destinadas ao público que se identifica com manifestações 


\section{VOZES

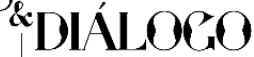

Itajaí, V. 20, n.01, jan-jun 2027

sociais, ambientais e até políticas, como as causas LGBTQ+, que são uma grande pauta de defesa da marca ${ }^{4}$.

É por entender que o comportamento de um seguidor em uma determinada rede social da Internet não é igual ao de outro, que representamos no gráfico a seguir a recorrência do uso dessas seis categorias em cada uma das três redes sociais analisadas.

\section{Gráfico 1 - Uso das estratégias de engajamento nas redes sociais da Netflix Brasil}

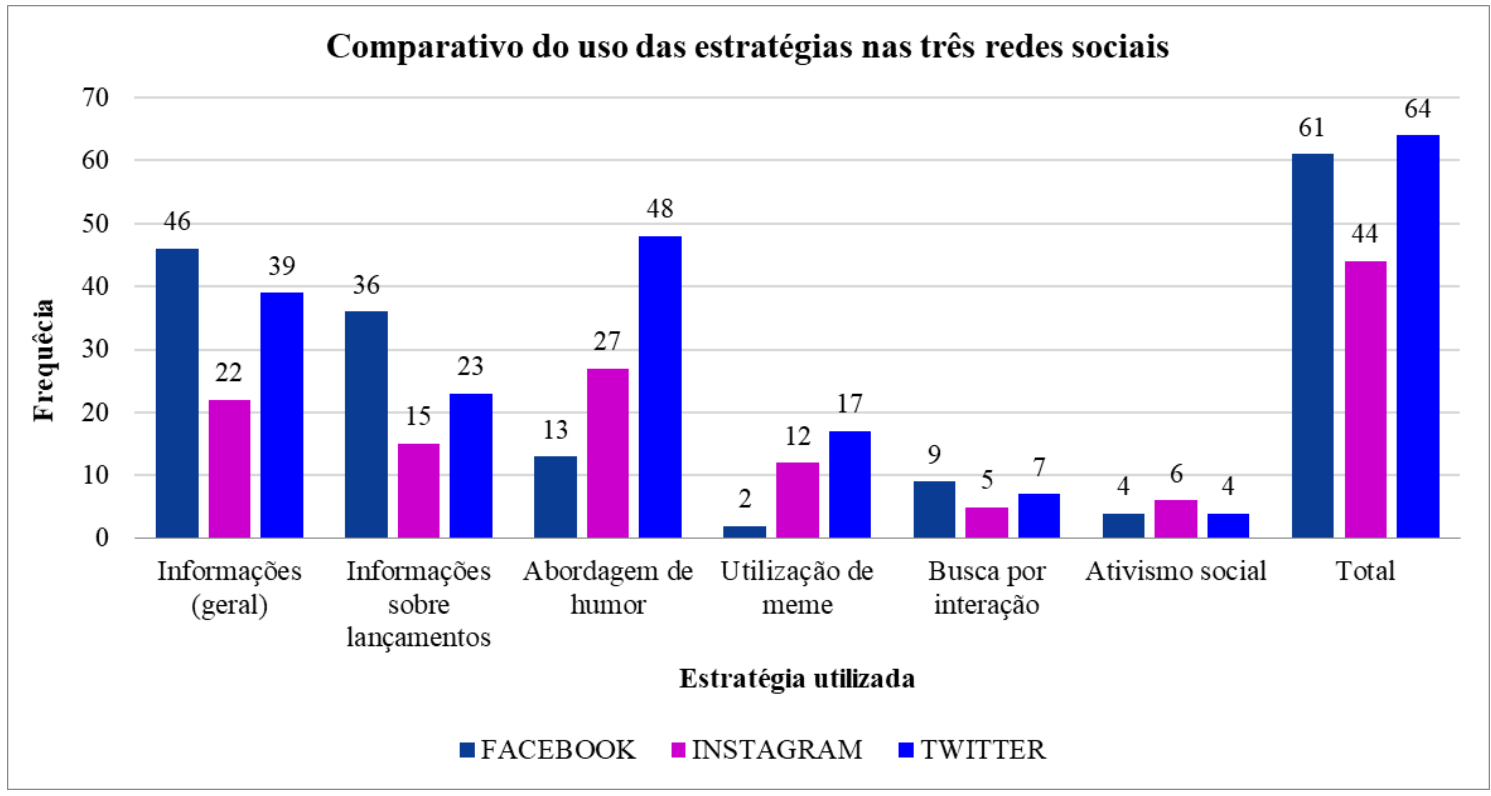

Fonte: As autoras (2020).

Ao observar o gráfico 1, percebemos que cada estratégia de engajamento da Netflix Brasil é utilizada de maneira e frequência diferentes, de acordo com a rede social em que o conteúdo da empresa é veiculado. Vale destacar que a incidência de cada uma das estratégias encontradas é superior ao número total de publicações, uma vez que, na maioria das postagens, o perfil da Netflix Brasil utilizou mais de uma estratégia de engajamento para se comunicar com o público.

No Facebook foram analisadas 61 publicações no período de um mês, sendo veiculadas por meio de vídeos (75\% dos posts), imagens $(20 \%)$ e textos $(5 \%)$. Como as publicações analisadas e o gráfico demonstram, o objetivo da página nesta rede social é manter seus seguidores informados sobre lançamentos e novidades em geral, ao mesmo tempo em que busca manter um relacionamento de amizade com eles. É por isso que, apesar de identificarmos no Facebook todas as seis estratégias citadas anteriormente, as que

\footnotetext{
${ }^{4}$ As causas LGBTQ+ são pautas de defesa da Netflix, que recorrentemente explicita seu posicionamento em distintas redes sociais, como é o caso da seguinte publicação no Twitter (Disponível em: https://twitter.com/NetflixBrasil/status/1764285753230315520) e no Facebook (Disponível em: https://www.facebook.com/netflixbrasil/videos/1142255879164537). Acesso em: 19 jun. 2021.
} 


\section{VOZES $_{\text {\&IÁLORO }}^{\mid}$}

Itajaí, V. 20, n.01, jan-jun 2021

predominam nessa rede são as informações sobre lançamentos e sobre a plataforma - 82 incidências de informações gerais somadas às informações sobre lançamentos.

No Instagram o número de publicações coletadas foi de 44 (75\% imagens e $25 \%$ vídeos), em que verificamos que o objetivo da empresa é influenciar e se relacionar com seus seguidores. É por se adaptar ao perfil do público do Instagram que a Netflix adota uma postura mais despojada e menos institucional, apresenta uma frequência elevada da abordagem de humor, deixa o teor exclusivamente informativo em segundo plano, ao contrário do Facebook, e utiliza-se do humor para apresentar lançamentos e demais conteúdos - somando o uso de abordagens de humor e de memes constam 39 incidências.

Por fim, a terceira rede social analisada apresentou 64 publicações, sendo $50 \%$ delas em formato de vídeo, $25 \%$ com imagens, $15 \%$ apenas com textos e $10 \%$ com GIFs. O objetivo da empresa no Twitter, assim como no Instagram, é entreter e manter uma boa imagem entre os seguidores. Mesmo utilizando das seis estratégias identificadas, se apropria amplamente da abordagem de humor e uso dos memes para conquistar seu público - são 48 abordagens de humor e 17 usos de memes.

Percebemos que nas 169 postagens distribuídas nas redes sociais citadas, as três estratégias mais utilizadas são as informações sobre lançamentos, as informações sobre a empresa (geral) e a abordagem de humor. Além disso, é possível afirmar que a Netflix Brasil conhece seu público e as comunidades virtuais distintas que se formam em cada rede social. É visível que a empresa muitas vezes compartilha o mesmo assunto nas três redes sociais, diversificando apenas a maneira como difunde a mensagem.

Após a análise das estratégias, investigamos a classificação dos níveis de engajamento dos consumidores da Netflix em cada uma das redes sociais. Tal análise é feita a partir do levantamento quantitativo dos meios de interação dos seguidores, que são as reações (curtidas, haha, amei, etc.), os comentários e os compartilhamentos das publicações coletadas. O levantamento ocorreu através da tabulação do volume de interação com as Unidades de Contexto no Facebook, Instagram e Twitter.

Ao analisarmos o número de interações dos fãs nas redes sociais com as publicações da Netflix Brasil examinadas, constatamos que no Facebook houve 1.036.295 reações (curtidas), 312.669 comentários dos fãs, 190 respostas da Netflix e 268.943 compartilhamentos. Já no Instagram encontramos 7.944.862 reações (curtidas), 312.669 comentários, 121 respostas da Netflix e zero compartilhamentos. Por fim, no Twitter foram 1.509.674 reações (curtidas), 60.310 comentários, 298 respostas da Netflix e 275.607 compartilhamentos.

No período de um mês, visualizamos um número expressivo de contato entre os consumidores e a marca. A diferença da quantidade de reações nas publicações do Instagram em comparação ao Facebook e ao Twitter é significativa, o que pode ser explicado pelo fato de que esta é a única rede em que as pessoas não fazem compartilhamento das postagens, com foco principal voltado às curtidas. 


\section{VOZES $_{\text {\&IÁLORO }}^{\mid}$}

Itajaí, V. 20, n.01, jan-jun 2021

Compreendemos o engajamento como a participação dos usuários no desenvolvimento ou ampliação da comunicação de uma marca e vice-versa. Haven (2007, p. 5) reconhece o engajamento como algo que vai além do alcance e da frequência para medir "os reais sentimentos das pessoas em relação às marcas. Ele começa com o próprio relacionamento da marca e continua à medida que ela expande esse relacionamento para outros consumidores”. A partir disso, apreendemos a ideia de que engajamento não é só a mobilização do público diante de uma marca ou uma empresa, como também a maneira que esta empresa se porta para engajar-se com seus consumidores. Haven (2007, p. 04) afirma que o engajamento é uma junção de "envolvimento, interação, intimidade e influência”, propondo que o engajamento do público nas redes sociais da Internet deve ser medido a partir destes quatro parâmetros.

O envolvimento é percebido pelo número e tempo de visitas no perfil da empresa; a interação se dá pelos comentários, curtidas e conversas iniciadas (como um pedido de informação ou uma sugestão); já a intimidade é medida pelos sentimentos e opiniões que a pessoa demonstra pela empresa; e a influência é notável a partir do momento em que o sentimento da pessoa em relação à marca é tão forte que influencia os demais participantes da rede a tornarem-se fãs, consumirem e envolverem-se também. A partir desses níveis de engajamento, o autor identifica três tipos diferentes de participação dos consumidores: o participante passivo (passive participant), o semiativo (semiactive participant) e o fanático pela marca (brand zealot).

Esta mensuração proposta por Haven tem características similares ao proposto por Li (2011) em sua Pirâmide de Engajamento. Nela, a autora identifica níveis de envolvimento dos usuários das redes e os organiza no formato de uma pirâmide crescente. $\mathrm{Na}$ base desta pirâmide estão os observadores, que são os consumidores que estão presentes nas plataformas digitais apenas observando o conteúdo que as empresas produzem, sem opinar nem participar ativamente das discussões e produções. Logo acima, estão os usuários que, por considerarem o conteúdo relevante, participam com o ato de compartilhar e espalhar estes conteúdos em suas próprias redes. No meio desta pirâmide encontram-se os usuários que são ativos nos comentários online, contribuindo com opiniões e avaliações de temas específicos. Em seguida, os produtores são os usuários que efetivamente produzem conteúdo para suas próprias conexões em suas próprias redes. Por fim, no topo estão os moderadores ou curadores, que são os consumidores engajados de fato: os que investem tempo e dedicação em comentar, compartilhar, analisar os conteúdos e disseminar aquilo que consideram relevante para os demais, em fóruns de discussões, publicações em blogs, etc. Estes são os usuários mais apaixonados e entusiasmados, pois agem como membros do seu grupo, voluntariamente participando na criação do conteúdo e, por isto, estão no topo. Em suma, quanto mais acima um usuário encontra-se na pirâmide, maior o seu nível de engajamento. 


\section{VOZES $_{\text {\&IÁLORO }}^{\mid}$}

Itajaí, V. 20, n.01, jan-jun 2021

Assim, percebemos que as ações dos consumidores na Pirâmide de Engajamento de Li (a) ${ }^{5}$ seguem o mesmo fluxo de interação de Haven (b), pois, para que um consumidor chegue ao nível de ser um "moderador da marca" (a) ou um "fanático pela marca" (b), primeiro ele passa pela fase de observar (a), que é o mesmo passo de envolver-se (b); depois, por meio de compartilhamentos (a) passa a interagir (b) até avançar para o comentar e se tornar produtor de conteúdo (a), que ocorre quando já está mais íntimo da marca ou empresa (b) até, ademais, tornar-se o chamado curador ou moderador da marca (a), que é a pessoa que influencia (b) os outros usuários a engajarem-se também.

Para exemplificar melhor a concordância dos conceitos de ambos autores, elaboramos um Fluxograma de Engajamento nas Redes Sociais. Nele, as ações dos consumidores e seguidores que Li (2011) elenca avançam no mesmo fluxo do nível de engajamento de Haven (2007), como demonstrado na representação gráfica:

Figura 1 - Fluxograma de engajamento

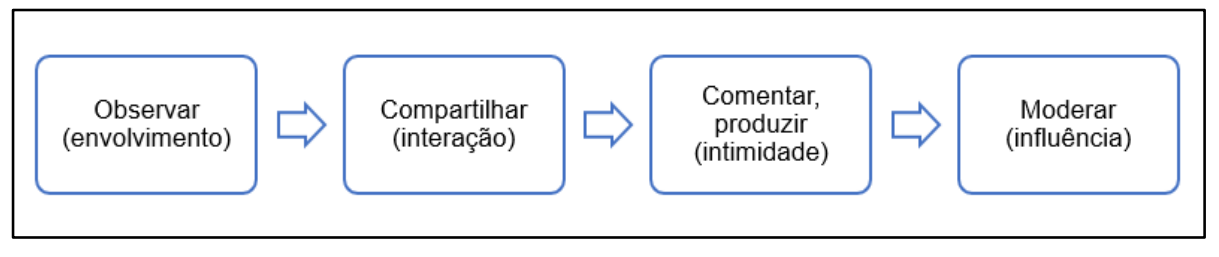

Fonte: As autoras (2020).

Tais conceituações, cruzadas e em conversação, demonstram as categorias que utilizamos a priori para estabelecer os caminhos da análise do engajamento dos seguidores da Netflix Brasil. Seguindo o exposto, o primeiro nível de engajamento é a observação, o que representa o ato de envolver-se com o perfil da empresa. Para mensurar a quantidade de observações das postagens levamos em consideração o número de reações registradas em cada uma delas. Assim, em uma visão superficial dos conteúdos, avaliamos um grande nível de engajamento do público por envolvimento/observação.

Todavia, as conclusões sobre o fluxograma de engajamento da Netflix não podem ser fundamentadas sem que tenhamos conhecimento do motivo pelo qual ocorre determinada classificação. Considerando que o nível de engajamento por meio de reações é o que mais se destaca, selecionamos as 15 postagens mais curtidas em cada um dos sites de rede social da Netflix Brasil para verificar o conteúdo e as razões pelas quais os seguidores engajam-se. O número de postagens selecionadas para esta verificação justificase, pois as 15 postagens com mais interação possuem as particularidades necessárias para indicar o que envolve o público e o nível de engajamento.

\footnotetext{
${ }^{5}$ Estabelecemos o elemento (a) como referência à Pirâmide de Engajamento de Li (2011) e o elemento (b) como referência ao fluxo de engajamento de Haven (2007) para correlacionar os termos dos autores de maneira dinâmica e didática.
} 


\section{VOZES $_{\text {\&DÁLORO }}^{\mid}$}

Itajaí, V. 20, n.01, jan-jun 2021

Vale destacar aqui que não é apenas o assunto ou o conteúdo da publicação que influenciam no engajamento. Existe também um mecanismo das próprias redes sociais que impulsiona a entrega do conteúdo e o aumento do engajamento. Esse mecanismo é chamado de algoritmo.

Segundo Bertocchi e Corrêa (2012, p. 07), o algoritmo nas redes sociais "é utilizado especialmente para ordenar elementos (dados sobre outros usuários) por critério de importância (definida pelo programador da empresa)". Deste modo, quanto mais engajado o seguidor da Netflix estiver com o conteúdo da página, maior a frequência com a qual as postagens da empresa aparecerão para essa pessoa.

Para compreender o nível de engajamento no Facebook, exploramos o conteúdo de cada uma das 15 postagens mais curtidas. É interessante ressaltar que a quantidade de reações visualizadas em cada publicação tem uma conformidade com o número total de compartilhamentos e comentários, que concordantemente acabam por ter resultados mais elevados, tal como as reações. Esta paridade pode ser visualizada no quadro 1 a seguir.

\section{Quadro 1 - Interações dos consumidores da Netflix no Facebook}

\begin{tabular}{|c|c|c|c|c|}
\hline CONTEÚDO DA PUBLICAÇÄO & $\begin{array}{l}\text { REAÇŌES } \\
\text { (CURTIDAS) }\end{array}$ & $\begin{array}{c}\text { COMENTÁRIOS } \\
\text { DOS FÄS }\end{array}$ & $\begin{array}{l}\text { RESPOSTAS } \\
\text { DA NETFLIX }\end{array}$ & $\begin{array}{l}\text { COMPARTILHA- } \\
\text { MENTOS }\end{array}$ \\
\hline Trailer da $3^{\mathrm{a}}$ temporada de "La Casa de Papel" & 174.623 & 100.207 & 3 & 120.000 \\
\hline Pôster da nova série "The Witcher" & 110.066 & 18.651 & 5 & 19.000 \\
\hline Video sobre renovação da série "Lúcifer" & 108.197 & 37.055 & 3 & 43.000 \\
\hline Pôster da $3^{\text {a }}$ temporada de "La Casa de Papel" & 67.134 & 12.821 & 0 & 10.000 \\
\hline Trailer da $3^{\mathrm{a}}$ temporada de "Stranger Things" & 57.579 & 14.276 & 5 & 22.000 \\
\hline Poster da $3^{\circ}$ temporada de "Stranger Things" & 31.696 & 6.101 & 2 & 4.500 \\
\hline Vídeo humorístico "Stranger Antenna" & 27.392 & 4.233 & 10 & 4.500 \\
\hline Calendário com lançamentos do mês & 25.301 & 8.186 & 0 & 2.200 \\
\hline Texto interativo sobre a série "Dark" & 24.626 & 5.051 & 0 & 1.700 \\
\hline Texto com teoria da série "La Casa de Papel" & 20.896 & 2.715 & 6 & 1.200 \\
\hline Capa do Facebook com temática LGBTQ+ & 20.637 & 1.626 & 4 & 211 \\
\hline Trailer da última temporada de "OITNB" & 20.172 & 4.224 & 4 & 6.400 \\
\hline Divulgação de séries LGBTQ+ para maratonar & 17.708 & 4.205 & 15 & 4.200 \\
\hline Trailer da nova série "O Cristal Encatado" & 17.362 & 3.236 & 4 & 1.800 \\
\hline Indicação de filmes LGBTQ+ para maratonar & 13.417 & 4.925 & 12 & 750 \\
\hline
\end{tabular}

Fonte: As autoras (2020).

Com base nos dados organizados, percebemos que o Facebook da Netflix Brasil obtém engajamento em publicações voltadas para as informações de lançamento, que é uma das estratégias mais utilizadas pela empresa nesta rede. Das reações observadas, ainda que constituídas de elementos negativos (como reação de raiva ou tristeza), as reações positivas manifestam-se em maior volume.

É notável que a empresa conquista compartilhamentos quando a publicação é atrativa aos fãs, pois propagam a novidade às suas conexões. Os comentários (mesmo que 


\section{VOZES $_{\& \text { DIÁLORO }}^{\downarrow}$}

Itajaí, V. 20, n.01, jan-jun 2021

produzidos por apenas $0,5 \%$ do total de seguidores) não são escassos, o que demanda que a Netflix filtre quais responderá. No que se refere ao relacionamento a partir destes comentários, o processo ocorre tanto entre usuários quanto entre eles e a marca - esta última com menos frequência. Quando isso ocorre, a Netflix faz questão de demonstrar e defender aquilo que acredita e considera como valores da marca. O que comprova esta afirmação é que as publicações que mais obtiveram interação do perfil com os usuários são de cunho social, seguidas daquelas com abordagem de humor.

A partir do fluxograma desenvolvido, verificamos que no Facebook há a presença de engajamento dos consumidores de três formas, que são, por ordem de frequência: observação (quando o engajamento se dá pelo envolvimento através de curtidas), intimidade (o engajamento se dá pela comunicação nos comentários) e interação (os seguidores engajam-se ao compartilhar a postagem em seus perfis pessoais).

É interessante verificar que no nível de engajamento do Facebook há mais intimidade do que interação, o que significa que os fãs estão mais interessados em manter um contato de diálogo com a marca do que compartilhar o conteúdo para que suas conexões no perfil e consumidores em potencial tenham acesso. A intimidade faz com que os laços entre a Netflix Brasil e os seus seguidores no Facebook se estreitem, o que levaria estes seguidores a avançarem para o nível mais elevado de engajamento.

Dentro do corpus desta pesquisa não há elementos que contemplem a análise de cada um dos fãs da Netflix para avaliar se classificam-se como moderadores. No entanto, em meio às publicações analisadas, destaca-se uma específica, que consiste num compilado de quatro capturas de tela com tweets de fãs da Netflix que assistiram ao filme LGBTQ+ "Elisa e Marcela" e não apenas indicam a produção aos seus seguidores, como exaltam as qualidades de direção, fotografia e roteiro da produção que relata a história real do casal que carrega o nome do filme. Ao compartilhar com seu público os comentários emitidos por espectadores do filme, a Netflix Brasil comprova que há engajamento por meio de influência. Ao avaliar e julgar as características do filme disponível na plataforma de streaming, os fãs moderados são carinhosamente intitulados como "Críticos Netflix", o que evidencia como a opinião deles tem importância para a produção de conteúdo, tanto informacional quanto recreativo.

Também exploramos no Instagram o contexto de cada uma das 15 postagens mais curtidas desta rede. Não consta análise quantitativa de compartilhamentos, pois este site de rede social não possui uma ferramenta que dimensione se houve compartilhamento por parte dos seguidores, apresentando apenas o número total de comentários e curtidas, como apresenta o quadro 2. 


\section{VOZES $_{\text {\&DÁLORO }}^{\mid}$}

Itajaí, V. 20, n.01, jan-jun 2021

Quadro 2 - Interações dos consumidores da Netflix no Instagram

\begin{tabular}{|c|c|c|c|}
\hline CONTEÚDO DA PUBLICAÇÄO & $\begin{array}{c}\text { REAÇÕES } \\
\text { (CURTIDAS) }\end{array}$ & $\begin{array}{c}\text { COMENTÁRIOS } \\
\text { DOS FÄS }\end{array}$ & $\begin{array}{c}\text { RESPOSTAS } \\
\text { DA NETFLIX }\end{array}$ \\
\hline Video sobre renovação da série "Lúcifer" & 592.707 & 55.353 & 3 \\
\hline Pôster da 3a temporada de "La Casa de Papel" & 508.728 & 10.030 & 0 \\
\hline Trailer da 3a temporada de "La Casa de Papel" & 462.381 & 44.831 & 5 \\
\hline Calendário com lançamentos de Julho & 359.782 & 11.576 & 7 \\
\hline Fotos c/ meme para divulgar filme "Cinderela Pop" & 358.069 & 4.162 & 1 \\
\hline Foto c/ meme sobre nome dos personagens "Rio" & 343.488 & 5.556 & 0 \\
\hline Calendário com lançamentos de Junho & 336.463 & 11.576 & 0 \\
\hline Teaser da nova temporada da série "Elite" & 310.071 & 16.997 & 3 \\
\hline Fotos c/ meme dos filmes em clima junino & 270.994 & 3.880 & 0 \\
\hline Pôster da 3a temporada de "Stranger Things" & 266.649 & 7.224 & 1 \\
\hline Foto c/ meme sobre série "Sex Education" & 259.106 & 3.369 & 0 \\
\hline Foto c/ meme sobre série "Good Girls" & 250.988 & 6.574 & 4 \\
\hline Fotos c/ cantadas para o Dia dos Namorados & 241.887 & 4.278 & 3 \\
\hline Foto para divulgar filme "Mistério no Mediterrâneo" & 223.994 & 5.333 & 5 \\
\hline Foto para divulgar série "Olhos que Condenam" & 192.038 & 5.321 & 3 \\
\hline
\end{tabular}

Fonte: As autoras (2020).

Diferente do Facebook que apresentou um grande índice de engajamento em publicações sobre lançamentos e divulgações de programações com teor $\mathrm{LGBTQ}^{+}$, no Instagram a Netflix Brasil conquista o engajamento dos fãs com postagens informativas em formato humorístico e com conteúdo descontraído com abordagem de memes.

Neste site, apesar de não haver a possibilidade de seus seguidores reagirem negativamente às postagens, eles expressam sua insatisfação nos comentários dos posts. Evidentemente, a Netflix Brasil adota uma persona que interage com os comentários apenas para "jogar conversa fora”, raramente respondendo às dúvidas ou críticas. No entanto, mesmo que com pouca interação da marca, os usuários procuram conversar entre si, construindo uma relação de afinidade com opiniões sobre o assunto abordado.

No Instagram, o nível de engajamento por comentários é 1,5\% superior ao nível de engajamento no Facebook, o que indica que há mais intimidade dos fãs com a marca nesta rede. Ademais, orientando-nos pelo fluxograma, verificamos que a presença de engajamento dos consumidores por observação é mais intensa, de modo que o envolvimento com a Netflix seja mais frequente nesta rede social do que nas demais.

Percebemos que pelos recursos restritos disponibilizados no Instagram, há apenas dois níveis de engajamento dos consumidores com a marca: o envolvimento e uma breve intimidade. Não houve identificação de engajamento por influência, sendo a própria marca o fator influenciador neste caso, mantendo a voz dos seguidores em segundo plano, apenas como fonte de feedback dos conteúdos e da comunicação. 


\section{VOZES \\ DIÁlORO}

Itajaí, V. 20, n.01, jan-jun 2021

O Twitter é a rede social em que a Netflix Brasil possui o menor número de seguidores, o que de maneira alguma representa a inexistência de engajamento. Para compreender como e por que ocorre o engajamento dos consumidores neste site, elencamos, no quadro 3 , as 15 publicações mais curtidas.

Quadro 3 - Interações dos consumidores da Netflix no Twitter

\begin{tabular}{|c|c|c|c|c|}
\hline CONTEÚDO DA PUBLICAÇÄO & $\begin{array}{c}\text { REAÇÕES } \\
\text { (CURTIDAS) }\end{array}$ & $\begin{array}{c}\text { COMENTÁRIOS } \\
\text { DOS FÄS }\end{array}$ & $\begin{array}{c}\text { RESPOSTAS } \\
\text { DA NETFLIX }\end{array}$ & $\begin{array}{c}\text { COMPARTILHA- } \\
\text { MENTOS }\end{array}$ \\
\hline Retweet postagem sobre "Harry Potter" na Netflix & 184.400 & 3.800 & 8 & 28.100 \\
\hline Texto c/ meme sobre cantada com Netflix & 134.100 & 2.400 & 0 & 27.300 \\
\hline Meme satirizando renovação da série "Lúcifer" & 126.000 & 8.100 & 8 & 24.800 \\
\hline Texto c/ meme sobre ASMR & 71.600 & 877 & 7 & 22.900 \\
\hline Meme sobre frio c/ personagem da série "Friends" & 65.400 & 578 & 2 & 24.900 \\
\hline Trailer da 3a temporada de "La Casa de Papel" & 64.700 & 2.900 & 5 & 20.100 \\
\hline Calendário com lançamentos do mês & 58.500 & 5.600 & 0 & 7.600 \\
\hline Trailer da 3a temporada de "Stranger Things" & 57.000 & 1.700 & 5 & 16.400 \\
\hline Foto humorística sobre assistir "Stranger Things" & 48.300 & 1.200 & 0 & 7.600 \\
\hline Foto humoristica sobre novos episódios & 44.100 & 1.200 & 0 & 8.900 \\
\hline Teaser da nova temporada da série "Elite" & 33.700 & 1.300 & 3 & 6.000 \\
\hline Foto c/ meme sobre a série "Good Girls" & 33.500 & 817 & 7 & 8.800 \\
\hline Texto humoristico sobre ator de "Harry Potter" & 32.700 & 3.500 & 15 & 2.000 \\
\hline Foto c/ meme sobre nome dos personagens "Rio" & 32.100 & 510 & 0 & 4.200 \\
\hline Video humoristico "Stranger Antenna" & 32.100 & 858 & 25 & 4.000 \\
\hline
\end{tabular}

Fonte: As autoras (2020).

Analisando o quadro, é evidente que há uma conformidade entre o número total de curtidas e o número total de compartilhamentos, apresentando resultados elevados em ambas categorias. Além disso, os dados organizados demonstram um número inferior de curtidas no Twitter se comparado ao Instagram, mas superior se comparado ao Facebook. Estas curtidas se dão, como podemos analisar nas cinco publicações com mais reações, em conteúdos humorísticos e com uso de meme. Os compartilhamentos (ou retweets) também são mais frequentes quando há abordagem de humor, demonstrando-nos o que atrai o engajamento dos usuários nesta rede social e confirmando as razões pelas quais a Netflix Brasil utiliza com assiduidade as estratégias voltadas para a diversão nesta rede.

Dos perfis da Netflix Brasil nas redes sociais, o do Twitter é o que tem menor número de seguidores, mas que resulta em maior número de engajamento através de comentários e respostas às publicações se comparado ao Facebook, que está na primeira posição neste quesito. Ainda que com muitas das estratégias voltadas para o humor, é notável que grande parte do relacionamento por comentários ocorre quando a empresa anuncia algum lançamento ou renovação, como foi o caso da série "Lúcifer", que obteve o maior número de comentários e foi a terceira postagem mais curtida no período da coleta. Apesar de haver uma quantidade significativa de intimidade, nem todos os comentários são 


\section{VOZES $_{\text {\&IÁLORO }}^{\mid}$}

Itajaí, V. 20, n.01, jan-jun 2021

positivos, muitos são caracterizados por cobranças relacionadas ao cancelamento das produções, por exemplo. Mesmo havendo comentários negativos e que demonstram insatisfação, não podemos desconsiderá-los como forma de engajamento, já que Haven (2007) explica que a intimidade - que se dá pela produção de comentários - é medida por todo e qualquer sentimento e opinião que o consumidor manifesta.

Assim, identificamos nesta rede social três níveis de engajamento: o envolvimento (pela abundância de curtidas), a interação (pela quantidade de compartilhamentos, que é superior às demais redes sociais) e a intimidade. Como nesta rede social há um nível relativo de intimidade, com alta incidência de comentários e produção de inteligência coletiva sobre a Netflix Brasil se comparado às outras redes, a empresa responde com muito mais frequência aos comentários. O número de diálogos chega, inclusive, a ser o dobro do que se encontra no Facebook.

Portanto, ao analisar o engajamento no Twitter, verificamos que a presença de engajamento dos consumidores por envolvimento (observação) é intensa, mas que o engajamento por interação e intimidade se destacam nesta rede. Identificamos que há mais engajamento por interação do que por intimidade, o que demonstra o quanto o público gosta de propagar aos seus seguidores o conteúdo comunicacional da Netflix Brasil no Twitter. No entanto, quando há intimidade é evidente que os consumidores não só emitem comentários destinados ao perfil da Netflix, como também às suas conexões. Neste momento, ele torna-se um consumidor produtor, engajado em produzir conteúdo para suas próprias conexões em seu próprio perfil. Em alguns casos, a empresa até reage à publicação ou responde, confirmando que nesta rede também há o engajamento de fãs moderadores, que se encontram no último nível do fluxograma.

Em um panorama geral, tomando os dados estatísticos no período de um mês, chegamos à conclusão de que, no Facebook, de quase 60 milhões de curtidores, apenas $1,8 \%$ deles engajam-se por observação e reação e menos de $0,5 \%$ deles compartilham e comentam as publicações. Já no Instagram, que tem quase 13 milhões de fãs, mais de $60 \%$ deles apresentam envolvimento com curtidas, enquanto apenas cerca de $2 \%$ produzem comentários. Por fim, no Twitter, dos 6,5 milhões de seguidores, uma média de 33\% deles reage com curtidas. Além disso, aproximadamente 4,5\% deles interagem com compartilhamento passivo das postagens e $1 \%$ deles com comentários nas publicações.

Com estas percentagens constatamos que a maioria dos fãs ainda está no estágio de envolvimento (por reações) com a marca nas três redes sociais. No entanto, os dados no Twitter demonstram que muitos já estão avançando para os níveis de interação (compartilhamento) e passando a ter intimidade (comentários e sentimentos). Com as capturas de tela de fãs que já apresentam engajamento por influência (moderadores) no Twitter, percebemos também que esta é a rede mais avançada em termos de nível de engajamento. No Instagram, a intimidade é mais desenvolvida que nas demais redes, mas ainda não se observa uma interação e uma relação que leve os fãs a tornarem-se 


\section{VOZES:}

Itajaí, V. 20, n.01, jan-jun 2021

moderadores da marca. De qualquer modo, estes níveis de engajamento são de grande importância para a Netflix Brasil, pois colaboram para que a empresa assimile como comunicar-se e em quais modelos de anúncios investir.

Tanto a interação mútua quanto o poder de produção dos fãs com a marca têm correlação com a popularidade do tema abordado na publicação, que interfere significantemente no nível de engajamento com a marca e também com outros usuários, independente da rede social analisada. Postagens com temas de caráter social ou de produções que estão em alta apresentam níveis de engajamento mais elevados do que as que não estão presentes nas conversas e discussões do público alvo nas redes sociais.

Dito isto, o engajamento dos consumidores e seguidores da Netflix Brasil se caracteriza entre os níveis de envolvimento e interação, com nuances de intimidade em desenvolvimento, o que poderia ser apresentado por Haven (2007) como consumidores com participação semiativa, já que o engajamento se dá em maior grau por três de quatro níveis do Fluxograma de Engajamento nas Redes Sociais.

\section{Considerações finais}

A análise das publicações da Netflix Brasil no Facebook, no Instagram e no Twitter apresentou as estratégias de comunicação mais utilizadas pela empresa. Com a observação do conteúdo das publicações, encontramos seis estratégias de engajamento que respondem ao primeiro aspecto do problema de pesquisa. Tais estratégias são, por ordem de frequência: as informações sobre lançamentos, as informações sobre a empresa, a abordagem de humor, a utilização de memes, a busca por interação e o ativismo social.

A caracterização das estratégias de engajamento da Netflix foi estabelecida com base na análise dos conteúdos centrais das publicações, já a caracterização dos níveis de engajamento foi possibilitada pela compreensão que Haven (2007) e Li (2011) empreitaram em trabalhos distintos, e que foram basilares para o desenvolvimento do Fluxograma de Engajamento nas Redes Sociais proposto neste trabalho.

O fluxograma foi a base para elencarmos o envolvimento dos fãs em quatro níveis: observação, interação, intimidade e influência. Com isto, compreendemos que o perfil dos seguidores da Netflix se caracteriza como um público que aprecia a troca de informações e o estabelecimento de relação com a empresa e os demais fãs, e é a partir deles que a Netflix Brasil desenvolve suas estratégias de comunicação digital.

Atestamos que a Netflix Brasil constrói seu capital social - ou seja, seu valor como marca entre o público que a circunda - pois utiliza de memes populares, imagens e discursos que já têm valor coletivo, de modo que a empresa não reforça a relevância da sua presença nas redes sociais por informações exclusivas e por seus serviços, mas sim pelas conexões que estabelece com os atores presentes nestas redes, que contribuem na 


\section{VOZES! \\ ¿DIÁl DRO}

Itajaí, V. 20, n.01, jan-jun 2027

construção simbólica da persona e da imagem da Netflix Brasil através da propagação de conteúdos relevantes da marca/para com a marca e conexões com demais atores.

\section{REFERÊNCIAS}

AMARAL, M. R. do. O valor do Netflix para o consumidor brasileiro. 66 f. 2016. Dissertação (Mestrado em Gestão Empresarial) - Escola Brasileira de Administração Pública e de Empresas, Fundação Getúlio Vargas, Rio de Janeiro, 2016.

BARDIN, L. Análise de conteúdo. São Paulo: Edições 70, 2011.

CORRÊA, E.S.; BERTOCCHI, D. O algoritmo curador: O papel do comunicador num cenário de curadoria algorítmica de informação. In: XXI ENCONTRO ANUAL DA COMPÓS, 21, Juiz de Fora. Anais... Juiz de Fora: UFJF/E-Compós, 2012.

HAVEN, B. Marketing's New Key Metric Engagement. Marketing Leadership professionals. Forrester Research, Inc. ago. 2007.

LEMOS, A. Cibercultura: tecnologia e vida social na cultura contemporânea. Porto Alegre: Sulina, 2002.

LI, C. Liderança aberta: como as mídias sociais transformam o modo de liderarmos. São Paulo: Évora, 2011.

NORTON, I. Netflix, TV expandida e intermidialidade em Stranger Things e 3\% - três por cento. Revista Temática, ano XIV, v. 02, p. 79-96, 2018.

RICCIULLI, S.L.S. A comunicação da Netflix com seus usuários: Web semântica, Smart Data e Redes Sociais Digitais como elementos de processos comunicacionais no ciberespaço. 122 f. Dissertação (Mestrado em Comunicação) - Faculdade Cásper Líbero, São Paulo, 2017. 